\title{
Trophic relationships and oceanography on and around a small offshore bank
}

\author{
Peter T. Stevick ${ }^{1,2, *}$, Lewis S. Incze ${ }^{1, * *}$, Scott D. Kraus ${ }^{2}$, Shale Rosen ${ }^{3}$, \\ Nicholas Wolff ${ }^{1}$, Adam Baukus ${ }^{1}$ \\ ${ }^{1}$ Aquatic Systems Group, University of Southern Maine, and ${ }^{3}$ Gulf of Maine Research Institute, \\ 350 Commercial Street, Portland, Maine 04101, USA \\ ${ }^{2}$ Edgerton Research Laboratory, New England Aquarium, Central Wharf, Boston, Massachusetts 02110, USA
}

\begin{abstract}
Small offshore banks may be sites of intense feeding by upper trophic level predators. We studied the distribution of cetaceans, seabirds, pelagic fish, euphausiids and zooplankton over a $9 \times 15 \mathrm{~km}$ bank to determine the conditions and processes that concentrated prey there and to examine the relative importance of bottom-up or top-down controls. Euphausiids were the primary prey during most foraging activity. While these were widespread in subsurface waters, foraging was concentrated on dense surface swarms that formed during daylight hours over 2 small crests. Internal wave passage resulted in upward movement and concentration of euphausiids in these areas through a coupling of physical processes and euphausiid behavior, resulting in surface swarms. Thus, internal waves appear to provide a critical mechanism enhancing trophic energy transfer. The formation of dense, localized and accessible prey concentrations was more important to foraging than was the overall available prey biomass. The estimated maximum daily consumption of euphausiids by cetaceans, seabirds and herring combined was $<0.4 \%$ of the estimated instantaneous euphausiid biomass, and top-down control was unlikely to have substantially influenced euphausiid biomass at this site. Some predator species that do not prey extensively on euphausiids or herring were more prevalent in off-bank waters. The scales of predictability and the temporal dynamics of such features determine the manner in which populations of upper trophic level organisms utilize a variable environment.
\end{abstract}

KEY WORDS: Foraging ecology · Euphausiid · Internal wave · Consumption · Cetacean · Seabird

\section{INTRODUCTION}

The marine environment exhibits a hierarchical structure of patchiness that changes with varying levels of predictability (Kotliar \& Wiens 1990). As biological organisms track the resources that they require across this variable environment, this patchiness leads them to aggregate (Fauchald et al. 2000). This spatial and temporal heterogeneity poses challenges for predators from copepods to whales, and a variety of adaptive strategies have evolved in organisms at all trophic levels (Mayo \& Marx 1990, Montevecchi \& Myers 1995). Understanding the nature and complexity of biological patchiness is fundamental to under- standing how ocean ecosystems function and change over time. In turn, this knowledge is essential for effective, integrated management of human activities in the marine environment (Link 2002).

There is a growing but still limited understanding of the processes that lead to patchiness at sea and how predators adapt to spatial and temporal variation in resources. In any locality, multiple physical features may act simultaneously to influence species composition, distribution and behavior, such as tidal and subtidal currents, convergent and divergent flows, shear, thermal stratification and internal waves. Thus, no single physical process dominates temporal variability in biological processes. These relationships may be subtle, 
and environmental correlates demonstrate both seasonal variation (Campana \& Joyce 2004) and scale dependence (Montevecchi \& Myers 1995). Physical conditions are transitory and both predator and prey are highly mobile, so relationships between oceanographic conditions and marine organisms are frequently difficult to establish. Multiple biological interactions (e.g. competition, predation and reproduction) also influence the distribution of organisms (Ballance et al. 1997, Stevick et al. 2002). Additionally, organism size and mobility span many orders of magnitude, while predators, prey and physical mechanisms require different methods of sampling. This makes obtaining high-resolution synoptic measurements difficult.

One approach is to intensively study areas where the biomass of organisms is notably elevated compared to surrounding waters. Such areas are sometimes referred to as 'hotspots'. These are typically well defined spatially and are frequently characterized by the presence of higher trophic level vertebrates, such as birds, migratory fishes, cetaceans and pinnipeds (Schick et al. 2004, Cotté \& Simard 2005, Croll et al. 2005). A hotspot may involve very high biomass at just a few trophic levels, or it may involve a complex food web with multiple trophic levels, producing a hotspot for biodiversity as well as biomass.

Because dense aggregations of any trophic level require sufficient prey at a lower level, the formation of hotspots is likely to be driven by bottom-up processes. Bottom-up effects include conditions that generate locally elevated production or that lead to aggregations through combinations of advection and behavior (Cotté \& Simard 2005, Croll et al. 2005). Because of the importance of physical processes in the formation of hotspots, they are commonly associated with areas of steep bathymetric and hydrographic gradients (Baumgartner et al. 2003, Campana \& Joyce 2004), such as those occurring around banks and shoals (Coyle et al. 1992, Yen et al. 2004, Cotté \& Simard 2005). All birds and cetaceans are constrained in their foraging activities at depth by their diving capabilities. Given these constraints, prey at or near the surface are more readily exploited. Additionally, prey at the surface are unable to move above the surface to escape, so the air-sea barrier can serve as a concentrating mechanism.

Even if the physical locations of hotspots are predictable, the elevated feeding activities associated with them are often ephemeral, lasting from hours to weeks. The extent to which such declines in activity are due to bottom-up or top-down effects is not known. A change in the underlying processes that affect production or aggregation could be responsible (Hunt et al. 1998). Alternatively, predation may reduce the density and intensity of trophic interactions (Worm \& Myers 2003), leading to dispersal of prey patches or decreases in prey abundance.
In the present study we examine a hotspot over a small offshore bank. Small, isolated features are relatively easy to define and sample and are anticipated to be occupied more variably and for shorter periods of time than are larger features. Therefore, predators must exploit a network of such sites, foraging at each while conditions are favorable and then moving on. The predictability and temporal dynamics of these hotspots therefore become an important part of how populations of upper trophic level organisms utilize a variable environment.

\section{MATERIALS AND METHODS}

The study area is located $50 \mathrm{~km}$ from shore in neritic waters of the western Gulf of Maine and covers $1672 \mathrm{~km}^{2}$, including Platts Bank, Three Dory Ridge and

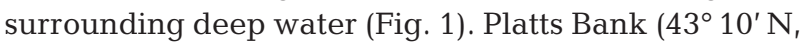
$69^{\circ} 40^{\prime} \mathrm{W}$ ) is a glacial deposit composed primarily of sand and gravel. When defined by the $100 \mathrm{~m}$ isobath, the bank is ca. $15 \mathrm{~km}$ in its longest dimension and has an area $<140 \mathrm{~km}^{2}$. It has 2 crests with minimum depths of $55 \mathrm{~m}$ each, separated by a trough 80 to $90 \mathrm{~m}$ deep. Three Dory Ridge, ca. $15 \mathrm{~km}$ long and $<5 \mathrm{~km}$ wide, consists of 3 low submarine peaks ca. 90 to $100 \mathrm{~m}$ deep. Waters elsewhere in the study area exceed $220 \mathrm{~m}$, with a mean depth of $154.5 \mathrm{~m}(\mathrm{SD}=34.0)$. The closest other substantial banks and ledges are located $40 \mathrm{~km}$ to the southeast and $20 \mathrm{~km}$ to the west of the study area. Platts Bank is located in an area of generally weak residual southerly flow (Pettigrew et al. 2005), but has strong semidiurnal tidal currents exceeding $40 \mathrm{~cm} \mathrm{~s}^{-1}$. Bathymetric data used in the present study have a horizontal resolution of $25 \mathrm{~m}$ and come from a recent multi-beam survey.

Aerial surveys were flown on 10 d from July 11 to 29 , 2005 to record the distribution and relative abundance of marine mammals, seabirds and large fish. Surveys were typically conducted in the morning or early afternoon and consisted of 6 transects, each $46 \mathrm{~km}$ long and spaced $5.5 \mathrm{~km}$ apart, oriented on an east-west axis to minimize interference from reflected sunlight (Fig. 1). Survey legs were flown at $185 \mathrm{~km} \mathrm{~h}^{-1}$ and an altitude of $230 \mathrm{~m}$ using a high-wing, twin-engine aircraft. Observation effort ( 2 observers) was concentrated from both sides of the plane perpendicular to the flight path. For most sightings of cetaceans, and in any instance when species identification or number of individuals was uncertain, search effort was interrupted while the plane circled to confirm identifications and number of individuals and to obtain a more precise location. Birds were recorded only within a $170 \mathrm{~m}$ strip on each side of the aircraft $\left(15^{\circ}\right.$ to $45^{\circ}$ of arc). Sightings of birds made while the plane was off track were not used in analyses 

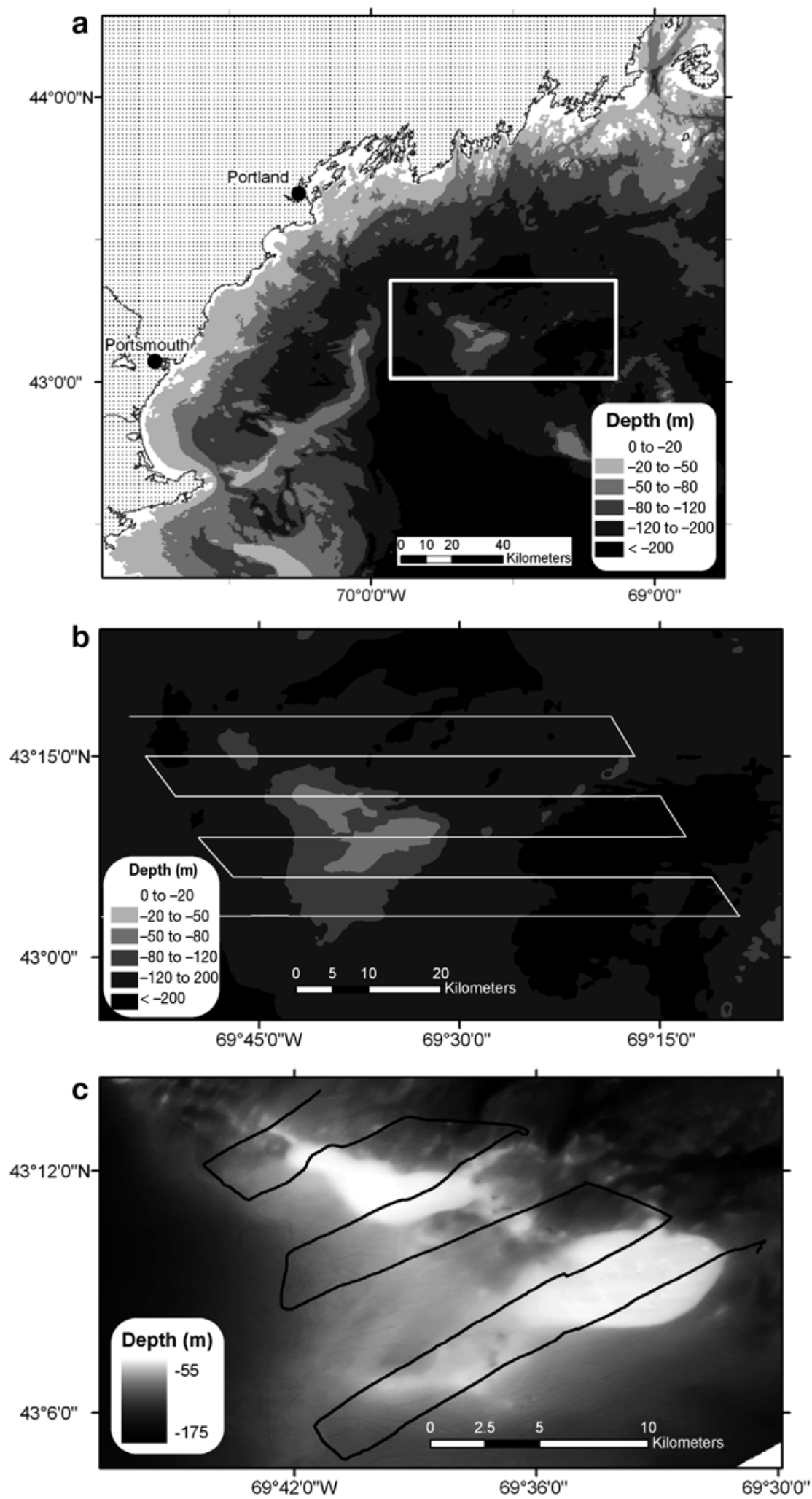

Fig. 1. (a) Study area (highlighted perimeter) in the western Gulf of Maine. Isobaths were selected to include the summits of a deep ridge (Three Dory Ridge) that extends northeasterly from Platts Bank. (b) Study area with aerial survey. (c) Close-up of the bank with the hydroacoustic survey course (solid line) of July 29 to 30 since this would bias bird sightings towards areas where cetaceans were observed. Data were recorded by a dedicated data recorder directly onto a computer linked to the plane's GPS. Location data are not available for most sightings on July 28 due to loss of communication between the GPS unit and the computer. These sightings were used for consumption estimates only.

The primary objective of these surveys was to record the distribution of different types of predators across the study area. As such, survey altitude was set to maximize the probability of detecting whales across the span between tracks, while also being low enough to allow identification of seabirds. This compromise may have somewhat restricted cetacean sightings at distance and also may have resulted in some under-recording of smaller seabirds, particularly stormpetrels, but allowed for all groups to be recorded synoptically from the same platform.

For those groups for which consumption was estimated, the aerial surveys were also used for estimating relative abundance. The density of seabirds observed within the $170 \mathrm{~m}$ strip on each side of the aircraft was determined and extrapolated to the survey area as a whole. The small study area and close line spacing allowed effectively $100 \%$ coverage for large cetaceans and groups of dolphins; individual animals sighted on one transect were frequently also sighted on the subsequent line. Thus, the number of individuals recorded on each survey is taken as the instantaneous abundance in the study area. There will be some negative bias in these counts of cetaceans because it was not possible to observe directly beneath the plane; some animals will have been missed because they were diving when the plane passed and detection probability will inevitably be lower for animals midway between tracks even with the very tight line spacing adopted.

Oceanographic sampling was conducted on 9 d from July 11 to 30, 2005, from a $14 \mathrm{~m}$ vessel. Seven of these 
corresponded to days when aerial surveys were flown. Unless otherwise stated, data were collected during daylight hours. Sampling included an internally recording Seabird CTD (SBE 19+) equipped with a Wet Labs fluorometer (WS3S), a $0.75 \mathrm{~m}$ diameter ring net with a $333 \mu \mathrm{m}$ mesh net and a $75 \mathrm{kHz}$ towed transducer/digital echosounder package (FEMTO Electronics DE9320).

Fixed stations always included a CTD/fluorometer profile, while sampling for zooplankton was conducted at a subset of stations. The $75 \mathrm{kHz}$ echosounder was variously deployed in 'station' mode (drifting or short tows), in long transects and in survey mode (covering all or most of the bank). Depth of the plankton net was monitored using a passive acoustic target and the vessel's depth sounder.

The ring net was usually towed vertically from near bottom to the surface. Surface tows were taken occasionally to sample dense aggregations of copepods and to collect euphausiids for identification and size measurements. Although we caught euphausiids when they were abundant near the surface, our predominantly daytime sampling and the limitations of our gear did not permit quantitative net sampling of euphausiids. A mechanical flowmeter mounted in the mouth of the net was used to estimate the volume sampled. Plankton samples were preserved in buffered formalin and completely analyzed in the laboratory for species and stage of all copepods and for family, genus or species of other taxa. Euphausiids were identified to species and stage, and adults were measured to the nearest $0.1 \mathrm{~mm}$ (total length from rear of eye socket to tip of telson, and width) using a dissecting microscope and calibrated digital camera system.

Sampling from the research vessel was distributed to compare on- and off-bank conditions for hydrographic structure and zooplankton community composition and abundance and to respond opportunistically to feeding patterns or other conditions that were observed from the plane or the vessel. Trained observers on the bridge recorded the presence of predators and their behavior.

Hydro-acoustics. The $75 \mathrm{kHz}$ transducer has a beam angle of $9.8^{\circ}$ and was mounted on a towing body which we deployed ca. $1.5 \mathrm{~m}$ off the vessel's side with the transducer ca. $2 \mathrm{~m}$ below the sea surface. Towing speed was maintained at 7.5 to $11 \mathrm{~km} \mathrm{~h}^{-1}$ depending on sea state. Acoustic data were logged onto computer using HDPS (Hydroacoustic Data Processing System) software. Geographical position was supplied to the logging software by a Garmin GPSMap 182 GPS equipped with Wide Area Augmentation System differential correction. Acoustic data were analyzed using HDPS software based upon visual interpretation of echograms as to whether the echos came from plankton or fish. An automated bottom removal algorithm was used to eliminate all data within $0.2 \mathrm{~m}$ of bottom. Water column and near-field portions of the echogram were edited manually.

The acoustic backscatter values ( $\mathrm{Sa}$ ) were converted to estimates of biomass for euphausiids and for the Atlantic herring Clupea harengus. For euphausiids, Sa values were converted to no. of ind. $\mathrm{m}^{-2}$ of sea surface, using the distorted-wave Born approximation model for acoustic scattering (Stanton \& Chu 2000, Lawson et al. 2006), run for the $75 \mathrm{kHz}$ frequency we employed. The length of individuals used in the calculation was taken from our net collections. Lengths were normally distributed so an arithmetic mean was used. Conversion from counts to biomass was based upon our length measurements and a published length:weight ratio for Meganyctiphanes norvegica (Kulka \& Corey 1982). Some of the backscatter was likely associated with the density structure and dynamics of the pycnocline (Lavery et al. 2003, Moum et al. 2003) and could not be distinguished from euphausiid returns. In the present study we have included all of the backscatter in the 'estimated abundance' for euphausiids. For herring, Sa values were converted to kg of herring based on methods described by Foote (1987) adjusted for $75 \mathrm{kHz}$ (Love 1971). Because euphausiids were distributed over the whole bank, the distance-weighted mean density was extrapolated across the entire bank. Herring were distributed in patches, so biomass was calculated based upon the subset of data on the north and south crests where herring were present.

The spatial distribution of euphausiids and herring over the bank was modeled using Generalised Additive Models (Wood 2006) for the most intensive acoustic survey, conducted on the night of July 29 to 30, covering $81.82 \mathrm{~km}$ of track line (Fig. 1). The best-fitting model for both taxa used a smooth of depth and 2-way smooths of depth with latitude and depth with longitude.

Prey consumption. Estimates of basal metabolic rate (BMR) for cetaceans used the model BMR = $293.11 M^{0.75}$, where $M$ is the estimated body mass $(\mathrm{kg})$ and BMR is expressed in $\mathrm{kJ} \mathrm{d}^{-1}$ (Kleiber 1975). For seabirds, $\mathrm{BMR}=416.3 M^{0.726}$ was used for procellariiformes (shearwaters and storm petrels), BMR = $544.9 M^{0.804}$ for charadriiformes (gulls and terns) and $\mathrm{BMR}=409.9 M^{0.823}$ for pelicaniformes (gannet) (Ellis \& Gabrielsen 2002). Estimates of BMR were calculated using published mass estimates (Kenney et al. 1985, Powers \& Backus 1987, Sibley 2000). The estimates of mass used here for some cetaceans (from Kenney et al. 1985) are lower than data reported from commercial catches due to potential sources of bias in catch data and regional variability in animal size. The lengths of both humpback Megaptera novaeangliae and fin whales Balaenoptera physalus in the western North 
Atlantic are below those reported elsewhere (Kenney et al. 1985, Stevick 1999).

An active metabolic rate of $2.8 \times$ BMR was used for cetaceans (Blix \& Folkow 1995) and seabirds (Powers \& Backus 1987), and corresponding assimilation rates were 0.8 (Lockyer 1976, 1981) and 0.75 (Powers \& Backus 1987). Many cetaceans store substantial energy reserves during the productive summer months to compensate for reduced or no feeding during migration or on winter breeding grounds. A conversion of 2.53 was used to account for increased foraging requirements of baleen whales during the peak summer feeding season (Sigurjónsson \& Vikingsson 1998). There are few data available on seasonal mass changes in Atlantic whitesided dolphins Lagenorhynchus acutus, so a more conservative conversion of 1.5 was used. No comparable conversion was used for birds as they store few lipids.

Most of these cetacean and seabird species are, to a greater or lesser extent, opportunistic feeders. Most have been described as taking both fish and euphusiids in the Gulf of Maine and may switch from one resource to the other based on availability. The basking shark Cetorhinus maximus, herring, euphausiids and some of the birds consume other parts of the plankton community, especially copepods. The 3 species of baleen whales seen in the present study have been described as eating between 90 and $95 \%$ fish in the Gulf of Maine (Kenney et al. 1985). During the present study, however, all observed surface feeding by fin whales and most by humpback whales was directed at euphausiids. The energetic value of herring was taken as $5.4 \mathrm{~kJ} \mathrm{~g}^{-1}$ (Steimle \& Terranova 1985); $3.2 \mathrm{~kJ} \mathrm{~g}^{-1}$ was used for euphausiids (Lockyer 1987). As the specific breakdown in prey consumed was not known, an intermediate value of $4.2 \mathrm{~kJ} \mathrm{~g}^{-1}$ was also used for fish and euphausiids combined in some analyses (Kenney et al. 1997). Annual prey consumption per unit of biomass (Q/B) for herring on Georges Bank is estimated as 4.59 (Pauly 1989), giving a daily consumption of $0.01258 \mathrm{~g}$ for each $\mathrm{g}$ of herring biomass. Energetic requirements for euphausiids are estimated to be $25 \%$ of body carbon $\mathrm{d}^{-1}$ (Clarke et al. 1988). The body carbon for euphausiids was estimated based upon $80 \%$ body water content and $48 \%$ dry weight of carbon (Nicol 2003).

The consumption model emphasizes foraging on the herring and euphausiid concentrations associated with Platts Bank, and some species of predators were therefore excluded. Molas Mola mola feed primarily on gelatinous zooplankton and were mostly found in deep water away from the bank. Basking sharks primarily feed on copepods and were not concentrated near the bank. Of the cetaceans, long-finned pilot whales Globicephala melas are primarily teuthovores and were exclusively found over deep water, while harbor porpoise Phocoena phocoena were sighted on only 2 occa- sions, and neither of these were near Platts Bank. Two sightings of large whales from deep water in the eastern part of the study area were not used because long dive times precluded identification. Seabirds that were uncommonly sighted were also excluded as their contribution to total food consumption was minimal.

\section{RESULTS}

\section{Physical setting}

Sea surface temperature (upper $2 \mathrm{~m}$ ) warmed from ca. 13.5 to $20^{\circ} \mathrm{C}$ from July 11 to 30 . The water column over Platts Bank was stratified in all of the hydrographic profiles, with a well-developed pycnocline and fluorescence maximum at ca. $12 \mathrm{~m}$ depth (but see later details on internal waves). The tidal range measured at the nearest coastal station (Cape Porpoise, Maine, $43.375^{\circ} \mathrm{N}$ ) ranged from $\leq 2.5 \mathrm{~m}$ early in the study to $>3.3 \mathrm{~m}$ from July 21 to 26 . Long, alternating parallel bands of slicks and roughened sea surfaces typical of passing internal waves (Jackson 2004) were common as were convergences and shears marked by floating seaweed, plankton (see below) and eddies.

\section{Zooplankton}

The net zooplankton was dominated by various life stages of the large calanoid copepod Calanus finmarchicus, which comprised $>85 \%$ of the sampled zooplankton by number. All stages of $C$. finmarchicus were present from eggs to copepodite stage CVI, with eggs, CIV and CV being the most numerous (average abundances of 6698, 4798 and $5221 \mathrm{~m}^{-2}$, respectively). In decreasing order of abundance we also found the copepods Pseudocalanus spp., Paracalanus parvus, Metridia spp., Centropages hamatis., Acartia spp., Temora longicornis, Oithona spp., Calanus hyperboreus and other invertebrates including cladocerans (Evadne and Podon spp.) and euphausiid larvae. Short surface tows in slicks when birds (herring and greater black-backed gulls, Wilson's storm-petrels and greater shearwaters) were feeding yielded immense concentration of Calanus spp. that we were not equipped to preserve or quantitatively subsample at the time. Euphausiids captured in the water column were all Meganyctiphanes norvegica, and adults ranged in size from 22.7 to $36.2 \mathrm{~mm}$ total length ( $\mathrm{n}=72$ measured, mean $\pm \mathrm{SD}=27.8 \pm 2.2$ ). We estimated the average live weight to be $5.7 \mathrm{~g}$ ind. ${ }^{-1}$ (Kulka \& Corey 1982).

Features consistent with scattering by planktonic organisms were observed in the $75 \mathrm{kHz}$ echograms. This backscatter was never deeper than $35 \mathrm{~m}$ from the 
surface, and the majority was in the upper $10 \mathrm{~m}$. These signals occurred above a backscatter layer with variable layered structures that we confirmed with CTD measurements to be in the pycnocline (see Warren et al. 2003). Sound scattering within this layer showed that internal waves with amplitudes of 3 to $13 \mathrm{~m}$ (most $<10 \mathrm{~m}$ ) and periods of ca. 4 to 8 min were common on the bank $(78 \%$ of the acoustic survey record shows these wave patterns, Fig. 2). The plankton backscatter was vertically compressed when the pycnocline echo shoaled toward the surface in front of an advancing wave crest. Serendipitously, we were able to match the backscatter signal from above the pycnocline with euphausiids during some surface swarming events (Fig. 2, and next paragraph). Our net samples did not reveal other planktonic organisms that are strong sound scatterers and sometimes abundant in the Gulf of Maine, such as siphonophores (which can leave a trace when nets are pulled slowly, as in vertical tows) and pteropods (which would be retained by the nets) (De Robertis 2001, Warren et al. 2001).

Euphausiid surface swarms were common during daylight on the bank's northern crest. We frequently were in a position (on the plane or the boat) to visually see these swarms form as a broad school of euphausiids rose rapidly from below. During shoaling events watched from the boat, euphausiids had similar directional and attitudinal orientations and regular spacing among them that can be characterized as schooling (1 to 3 body

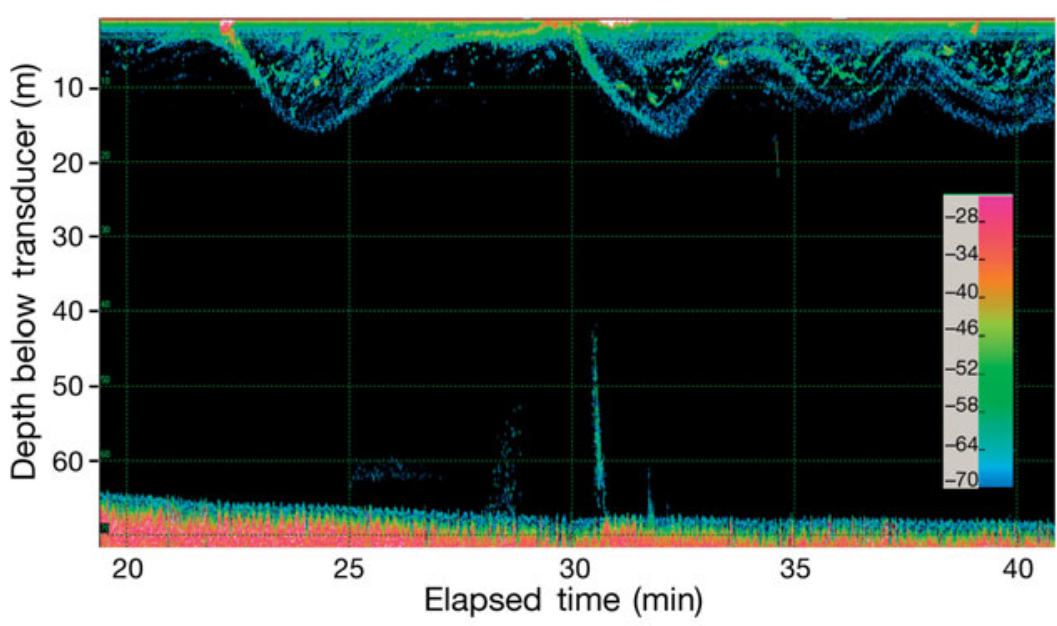

Fig. 2. Acoustic backscatter $(75 \mathrm{kHz})$ recorded near the northern crest of Platts Bank, July 20, 2005, 19:46 to 20:08 h, while the vessel drifted $330 \mathrm{~m}$ at $0.26 \mathrm{~m} \mathrm{~s}^{-1}$. The undulating bottom boundary of the surface mixed layer corresponds to the pycnocline and shows the passage of internal waves through the sampled area. The upper layer is replete with backscattering; the high near-surface backscatter at elapsed times of $\sim 22.5$ and 29 min was associated with sudden surface swarming of euphausiids, Meganyctiphanes norvegica (that is, visual confirmation of timing, taxon and high abundance). Wave periods and amplitudes shown in this short record are typical of wave packets recorded throughout the present study; the 2 confirmed swarms of euphausiids were qualitatively typical of dense swarms on the bank lengths typify our photographs of the swarms, see O'Brien 1987). Analysis of photographs of the patches when they first appeared at the surface gave estimates of $>950$ euphausiids $\mathrm{m}^{-2}$. Estimating that we were able to identify and count euphausiids to a depth of $0.5 \mathrm{~m}$ in these photos yields a conservative estimate of euphausiid concentration of $>1500 \mathrm{~m}^{-3}$ in the top $1 \mathrm{~m}$. If our visual depth of field were less, the estimate would be multiplied accordingly. Photos taken in the water confirm that the surface swarms, while schooling, extend at least $1 \mathrm{~m}$ deep. Despite these observations of schooling behavior, we will continue to use the more general terms 'swarm' or 'patch' because we could not make close-up of all the patches we saw and because the ly orderly patterns of behavior associated with were often disrupted by strong horizontal flows that led to filment-like distributions and very close packing of individuals. Moreover, when predators provided an appropriate description of the aggregation \& O'Dor 1985, O'Brien 1987). Surface swarms and usually lasted only a few minutes before the

appearance of euphausiids at the surface was 作 ring feeding voraciously on them. The ensuing mayhem was spectacular, but not the rule. The majority of euphausiid swarms that we observed were not followed by herring. Likewise, when we saw a swarm that was pursued by herring, we commonly saw other patches of euphausiids that had surfaced at the same time and were not being similarly pursued.

The acoustic surveys conducted the nights of July 20 to 21 and July 29 to 30 gave mean abundance estimates for euphausiids of 54 and $41 \mathrm{~m}^{-2}$ (coefficient of variation $[\mathrm{CV}]=0.14$ and 0.25 ), respectively, when the data were analyzed in groups of 40 pings. At 1 ping s ${ }^{-1}$ and an average transect speed of $2.6 \mathrm{~m} \mathrm{~s}^{-1}, 40$ pings translates to a distance of $104 \mathrm{~m}$. The maximum estimated abundance from the 2 surveys was 537 and $1549 \mathrm{~m}^{-2}$, respectively. Abundances greater than $300 \mathrm{~m}^{-2}$ comprised ca. $1 \%(\mathrm{n}=26)$ of the estimates in the earlier survey and ca. $3 \%(n=70)$ of those in the later survey. Reducing the averaging period to $10 \mathrm{~s}$ (a distance of $26 \mathrm{~m}$ along each transect) increased the maximum estimated abundances slightly $(\leq 51 \%)$ but did not signif- 

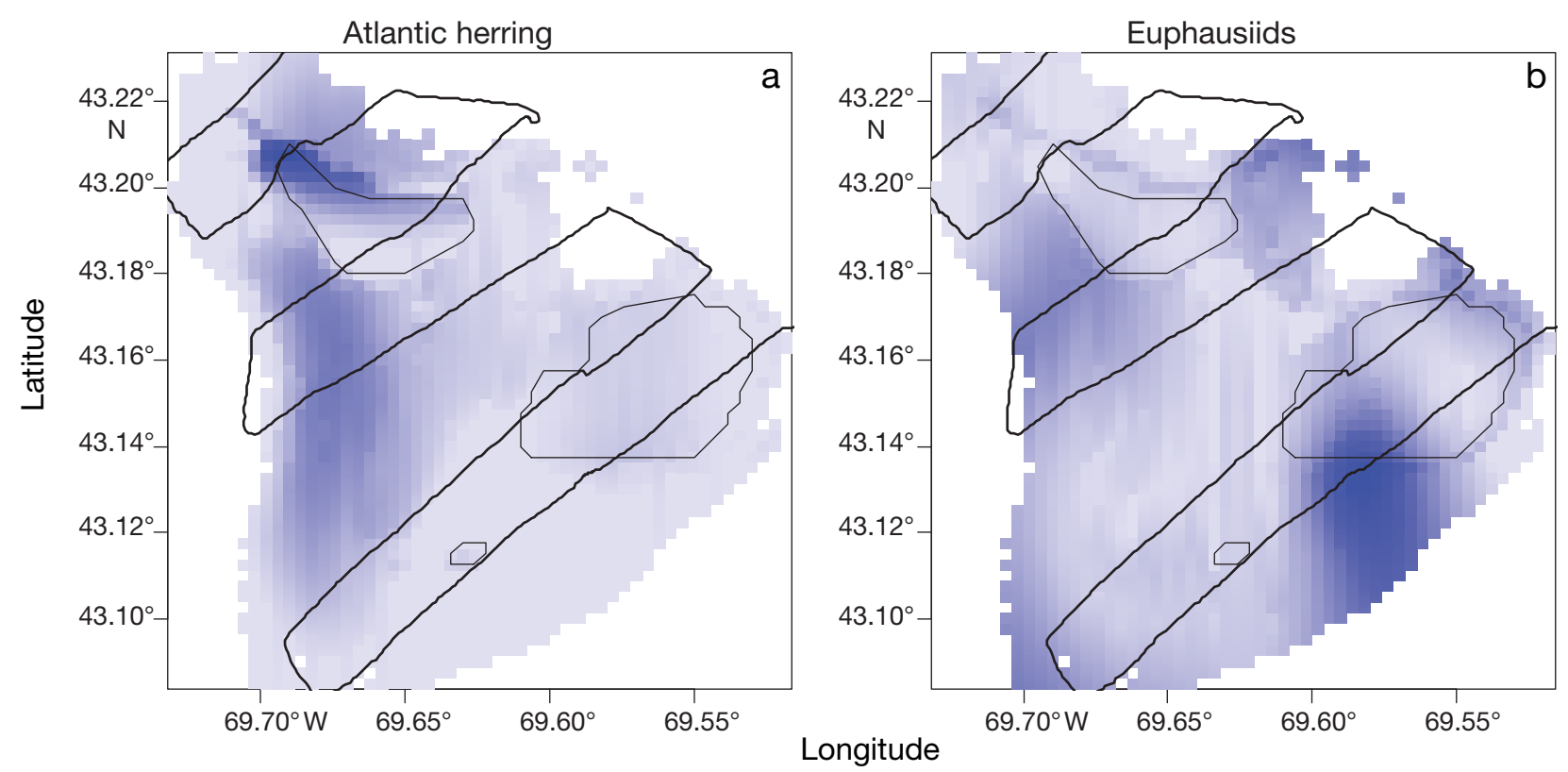

Fig. 3. Clupea harengus and Meganyctiphanes norvegica. Distribution of (a) Atlantic herring and (b) euphausiids using hydroacoustic data from surveys on July 29 to 30 collected along the track line illustrated by the heavy line. Only depths $<110 \mathrm{~m}$ are shown, and the ca. $65 \mathrm{~m}$ contour interval is presented. Euphausiid densities are ca. 1 order of magnitude greater than herring densities (max model output for euphausiids $4.5 \mathrm{~kg} \mathrm{~m}^{-1}$; herring $0.38 \mathrm{~kg} \mathrm{~m}^{-1}$ ). Herring were located almost exclusively over and near the 2 bank crests and the western edge of the bank. Euphausiids were distributed widely, though patchily across much of the bank

Table 1. Meganyctiphanes norvegica. Vertically integrated upper water column estimates of abundance during 2 acoustic surveys of Platts Bank using 2 data averaging intervals $(10 \mathrm{~s}$ and $40 \mathrm{~s}$ ) along the transects. Estimates are based on total backscatter at $75 \mathrm{kHz}$ and a sound scattering model for the size of euphausiids sampled (see text). The left column lists ranges of abundance estimates; columns to the right give the corresponding number of intervals with estimates falling within that range. For example, averaging over $10 \mathrm{~s}$ intervals in the second survey, there were 1507 intervals (48\% of all intervals) in which euphausiids occurred at estimated densities between 0 and $25 \mathrm{~m}^{-2}$. Intervals of 10 and $40 \mathrm{~s}$ had corresponding average length scales of 26 and $104 \mathrm{~m}$, respectively. Data are 'over-interpreted' to the extent that sound scattering associated with the pycnocline could not be distinguished from biological sound scattering, yet euphausiid estimates rarely reached densities observed at the surface

\begin{tabular}{|lcccc|}
\hline \multirow{2}{*}{$\begin{array}{l}\text { Estimated } \\
\text { abundance }\left(\text { no. m}^{-2}\right)\end{array}$} & \multicolumn{5}{c|}{ Number of 20 to 21} & \multicolumn{3}{c|}{ July 29 to 30} \\
& $10 \mathrm{~s}$ & $40 \mathrm{~s}$ & $10 \mathrm{~s}$ & $40 \mathrm{~s}$ \\
\hline $0-25$ & 849 & 193 & 1507 & 372 \\
$26-50$ & 572 & 158 & 509 & 131 \\
$51-75$ & 400 & 105 & 358 & 87 \\
$76-100$ & 235 & 59 & 213 & 58 \\
$101-125$ & 144 & 40 & 155 & 43 \\
$126-150$ & 86 & 22 & 129 & 22 \\
$151-300$ & 108 & 21 & 192 & 54 \\
$301-600$ & 16 & 5 & 38 & 9 \\
$601-1200$ & 2 & 0 & 24 & 5 \\
$>1200$ & 0 & 0 & 6 & 2 \\
Maximum & & & & \\
estimate $\left(\right.$ no. $\left.\mathrm{m}^{-2}\right)$ & 813 & 537 & 1995 & 1549 \\
\hline
\end{tabular}

icantly shift the relative frequency distribution of abundance estimates (Table 1). Backscatter associated with the pycnocline could not be identified everywhere in the record and was of varying strength; we did not attempt to isolate or remove these signals from the euphausiid estimates, which must therefore be regarded as partially overestimated.

The resulting biomass estimate for euphausiids on the bank from the July 29 to 30 survey was $35000 \mathrm{t}$ $(\mathrm{CV}=0.25)$. Euphausiids were distributed widely across the bank. The proportion of segments of survey track with detectable euphausiid traces (backscatter above the pycnocline) during the July 29 to 30 survey was 0.994. However, the distribution was highly patchy (Fig. 3). Patches occurred in different locations on the different surveys, and euphausiid concentrations were not notably associated with the crests or other areas of the bank or contiguous deeper regions.

\section{Herring}

The most extensive acoustic surveys were conducted during the night of July 29 to 30 . Herring were principally concentrated over the 2 crests of the bank and along the bank edges, with very little seen in waters $>100 \mathrm{~m}$ (Fig. 3). The proportion of transect segments with detectable herring during the July 29 to 30 survey was 0.368 . Biomass estimates indicated that there were 
$4000 \mathrm{t}$ of herring on the bank. Density was greatest on the northern crest of the bank with $3700 \mathrm{t}(\mathrm{CV}=0.49)$. There was $300 \mathrm{t}(\mathrm{CV}=0.02)$ on the southern crest. The vessel was not equipped to collect biological samples of fish, but jigging with rod and reel resulted in the catch of several herring, the small cod Gadus morhua and haddock Melanogrammus aeglefinus. The herring ranged from 28 to $31 \mathrm{~cm}$ (total length). Herring that were seen feeding on euphausiids at the surface appeared to be of similar size.

\section{Seabirds}

Species identification of seabirds was not always possible from the aircraft, but several groups of birds were prominent. Gulls were by far the most numerous of the seabirds. Local gulls of the genus Larus are trophically and ecologically similar and were treated together here. Similarly, no attempt was made to distinguish among the Sterna or Puffinus spp. All storm petrels were likely to be Wilson's Oceanites oceanicus. However, it is possible that some Leach's Oceanodroma leucorhoa were feeding in the area as well. Northern gannets Morus bassanus were the only other commonly sighted seabird. Other birds recorded included the northern fulmar Fulmaris glacialis, common eider Somateria mollissima and unidentified species of phalarope, alcid and jaeger.

The gulls, shearwaters and stormpetrels demonstrated non-random distributions relative to depths available in the study area (Table 2). All were more frequently encountered in the shoal waters over the bank than in deep water. Group size for gulls was also larger in water $<100 \mathrm{~m}$ in depth ( $W$ [Wilcoxon rank sum] $=5231.5, \mathrm{p}=0.0006)$. As scavengers, however, gulls are attracted to fishing boats. Since there were fishing boats operating in the area, it is more difficult to interpret the distribution data for these birds. A cluster analysis of large vertebrates associated by depth (Fig. 4) grouped shearwaters and storm-petrels in a cluster that contained species with sightings across a range of depth, but a concentration in shallower water over the bank. The gulls and northern gannet, along with basking shark, comprised a cluster of species that were the most evenly distributed across the study area. Terns clustered with species that were most commonly encountered in deeper water. No birds were in the cluster of species seen almost exclusively over the bank.

\section{Cetaceans and large pelagic fish}

Six species of cetaceans were observed. These included 3 mysticetes: humpback, fin and the minke whale Balaenoptera acutorostrata; and 3 odontocetes: Atlantic white-sided dolphins, pilot whales and harbor porpoise. Humpback whales were the most frequently sighted, white-sided dolphins the most numerous. In addition, 2 sightings of unidentified large whales were made. Because of the long dive times exhibited by these animals, specific identifications could not be made. Molas and basking sharks were commonly sighted. There were also 2 sightings of smaller sharks that were not identified to species.

Several species demonstrated non-random distributions in relationship to depth (Table 2). The 3 species of baleen whale were most closely associated with shoal water, though for fin whales this difference was not significant (perhaps due in part to the small number of sightings). Over the bank, these species were most commonly encountered near the 2 crests and along the steep contours (Fig. 5). They were not necessarily located directly over the crests, however. This was most notable at

Table 2. Platts Bank large vertebrate sightings. The number of sightings made and individuals sighted are given for each. The mean depth at which sightings were made is compared to the distribution of depths in the study area as $W=$ Wilcoxon rank sum test with continuity correction. Within taxa, species are listed in order of increasing mean depth of sightings. Some closely related species of birds were treated together. Shearwaters are predominantly greater with some sooty also present. Only Wilson's storm-petrels were identified to species, but some Leach's may also be present in the areas. Gulls are primarily herring and greater black-backed

\begin{tabular}{|lcccccc|}
\hline Taxa & Sightings & $\begin{array}{c}\text { Mean } \\
\text { group size }\end{array}$ & $\begin{array}{c}\text { Mean } \\
\text { depth }(\mathrm{m})\end{array}$ & SD & $W$ & $\mathrm{p}$ \\
\hline Cetaceans & & & & & & \\
$\quad$ Humpback whale & 79 & 1.41 & 88.5 & 35.2 & 8205 & $<0.0001$ \\
Minke whale & 9 & 1.00 & 81.6 & 15.2 & 381 & $<0.0001$ \\
Fin whale & 10 & 1.10 & 131.3 & 46.4 & 3536 & 0.1019 \\
White-sided dolphin & 32 & 38.78 & 124.0 & 44.1 & 9783 & 0.0001 \\
Pilot whale & 4 & 14.25 & 177.3 & 18.7 & 2667 & 0.2403 \\
Harbor porpoise & 2 & 3.00 & 174.1 & 5.58 & $-^{\mathrm{a}}$ & $-^{\mathrm{a}}$ \\
Seabirds & & & & & & \\
Shearwater & 56 & 7.34 & 136.0 & 42.3 & 22715 & 0.0003 \\
Storm-petrels & 61 & 9.43 & 142.7 & 35.8 & 24056 & 0.0045 \\
$\quad$ Northern gannet & 10 & 1.40 & 148.4 & 38.4 & 5875 & 0.8946 \\
Gulls & 246 & 5.43 & 146.7 & 35.7 & 114598 & 0.0015 \\
$\quad$ Terns & 32 & 2.56 & 154.7 & 41.9 & 17575 & 0.5219 \\
Fish & & & & & & \\
$\quad$ Molas & 119 & 1.05 & 164.6 & 30.7 & 73890 & 0.0040 \\
$\quad$ Basking shark & 51 & 110 & 148.0 & 37.0 & 27319 & 0.1590 \\
a Sample too small to test & & & & & \\
\hline
\end{tabular}




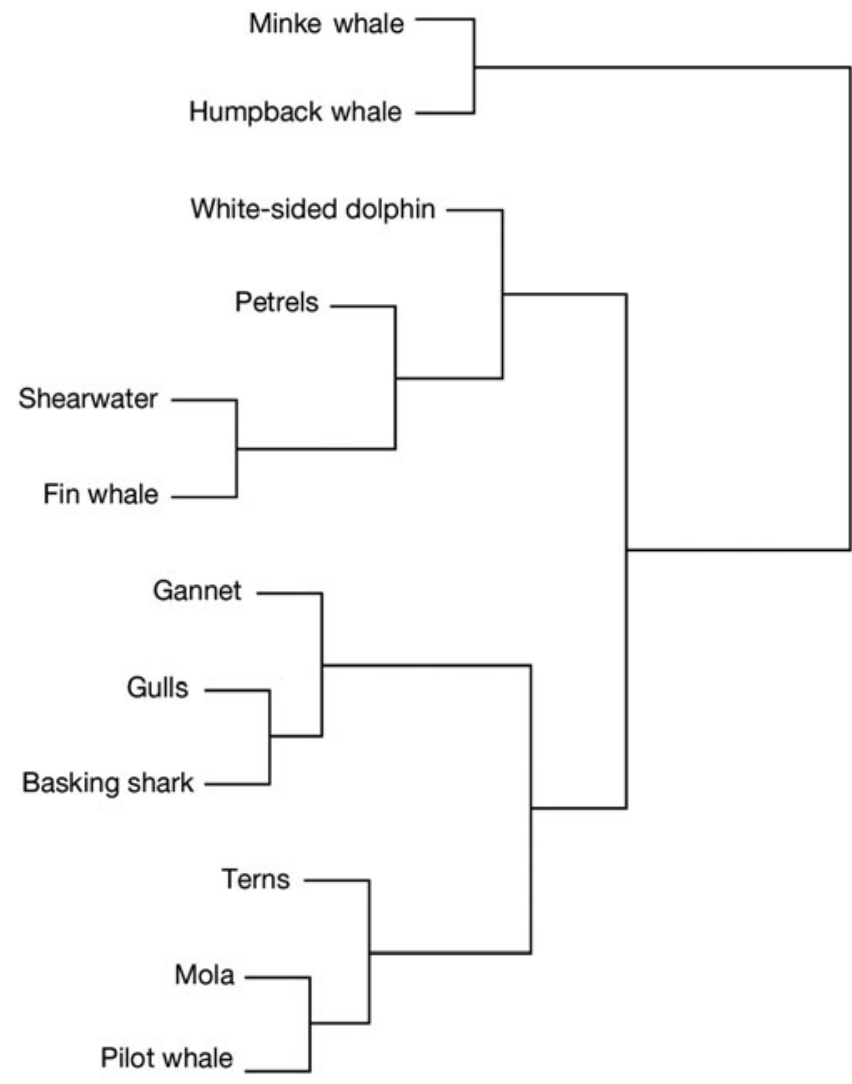

Fig. 4. The most commonly sighted large vertebrates in the study area clustered by similarity in depth distribution. A complete clustering algorithm is used. The upper cluster comprises those species most closely associated with the shoal waters of the bank. The next cluster represents species that were more prevalently but not exclusively seen near the bank. Below this is a cluster of species that were most widespread over the study area. The lowest cluster represents species affiliated with deep water

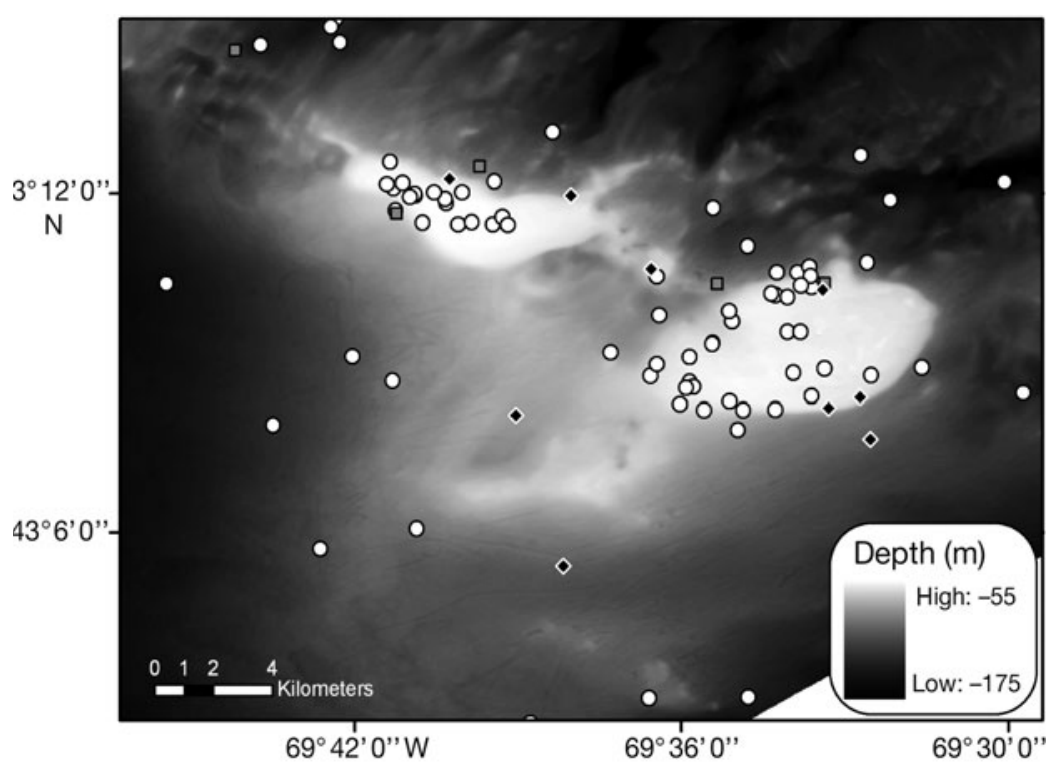

the southern crest where these whales were most abundant around the edges rather than over the peak. In contrast, molas were found at sites with a median depth significantly greater than the median depth of the study area overall. While pilot whales and harbor porpoise were exclusively found in deep water, the small number of sightings gave little or no power to demonstrate this. Basking sharks were widely distributed at a range of depth and, despite a large sample size, did not demonstrate a significant relationship with depth.

A cluster analysis of depth distribution by species indicated 4 groups (Fig. 4). Minke and humpback whales were most closely associated with shallow waters of the bank and segregated from all other species. At the other extreme were 3 taxa that did not demonstrate affinity for the bank region, including molas and pilot whales. Fin whales and white-sided dolphin were found more frequently near the bank, but also were sighted in deeper waters, while basking sharks fell in a cluster with other very widespread species.

\section{Trophic interactions}

The foraging activity that was observed was concentrated on the dense surface swarms of euphausiids. The formation of these surface swarms was sometimes abruptly followed by a large number of herring. When herring and euphausiids did co-occur, the herring preyed actively and heavily on the euphausiid patches. These euphausiid surface shoals, whether or not they were associated with herring, were very often preyed upon by fin or humpback whales and nearly inevitably by seabirds. The foraging activity of whales and birds was most intensively concentrated at the densest patches, and the whales and birds followed the formation of these patches as successive waves of them appeared.

Large vertebrates removed an estimated $20.3 \mathrm{t}$ of fish and crustacean prey from the study area each day during the present study (Table 3). Baleen whales were the largest con-

Fig. 5. Megaptera novaeangliae, Balaenoptera physalus and $B$. acutorostrata. Distribution of sightings of 3 baleen whale species made during 10 aerial surveys. Humpback whales $(\bigcirc)$ and minke whales $(\square)$ were most strongly associated with the bank overall and the 2 crests. Fin whales $(\bullet)$ were frequently sighted over the crests but were also seen regularly in deeper waters 
sumers. Because of their large mass and relatively high densities, humpback whales consumed nearly an order of magnitude more prey than did the other species. White-sided dolphins took nearly as much prey as did fin whales. Gulls consumed nearly 4 times the prey of all other birds combined. Since the energetic values of the 2 prey types differ somewhat, if all prey taken were herring, this would amount to $15.5 \mathrm{t} \mathrm{d}^{-1}$ of herring consumed, or 0.0039 of the estimated herring biomass. However, if euphausiids were the exclusive prey, then $22.4 \mathrm{t} \mathrm{d}^{-1}$, or 0.00065 of the estimated euphausiid biomass, was taken. Herring consumed $50.5 \mathrm{t} \mathrm{d}^{-1}$ of prey on Platts Bank. The biomass proportion of euphausiids in herring diet within the Gulf of Maine was reported to be 0.857 (Bowman et al. 2000). Thus, $43.2 \mathrm{t}$ of this consumption is anticipated to be euphausiids.

To obtain an estimate of the maximum potential daily consumption of euphausiids on the bank (Table 4), we first assumed that herring and all of the whales and birds studied (excluding basking sharks, molas and pilot whales, which were not anticipated to eat euphausiids) were taking euphausiids exclusively, even though some were certainly taking alternative prey. The area of Platts Bank to which the abundance estimate for euphausiids applies is a very small proportion (0.084) of the larger study area over which the abundance of predators is determined, further maximizing potential consumption estimates of euphausiids on the bank. Finally, as some of the estimates of predator abundance are imprecise and biases in these estimates are likely to be negative, high estimates of predator abundance (mean abundance + SD) were used.

Euphausiids consumed $839 \mathrm{t} \mathrm{d}^{-1}$ of carbon from Platts Bank. Of this, $0.54 \mathrm{t}$ $\mathrm{d}^{-1}$ was subsequently eaten by large predators and $1.04 \mathrm{t} \mathrm{d}^{-1}$ was taken by herring.

\section{DISCUSSION}

Platts Bank formed a consistent focal point for foraging activity by a range of species during the $20 \mathrm{~d}$ study. The foraging observed was largely confined to a small portion of bank that was only a small portion of the area surveyed. Several factors were involved: tidal and non-tidal transport onto the bank, the abundance of euphausiids in the surface layer and the apparent role of internal waves in enhancing surface concentrations of these prey. Although euphausiids are negatively phototactic, surface swarming of Meganyctiphanes norvegica has been reported at other locations in the Gulf of Maine (Nicol 1984), and fishermen say they often see 'red water' produced by krill on Platts Bank. The reason for the particular vertical distribution that makes krill subject to these physical processes, or what might prevent it, are subjects for further research. We

Table 4. Maximum estimated daily consumption of euphausiids on Platts Bank by major groups of predators surveyed. Since the proportion of euphausiids in the diet is not known with certainty, this table presents an upper limit by assuming that all predators are taking exclusively euphausiids. Additionally, the estimate is based on a high estimate (mean + SD) of abundance for each taxonomic group. The proportion of the euphausiid biomass consumed is presented based on both the best estimate of euphausiid abundance and a low estimate (best estimate - SD)

\begin{tabular}{|lcccc|}
\hline Taxa & $\begin{array}{c}\text { High estimate of } \\
\text { consumption (t) }\end{array}$ & $\begin{array}{c}\text { Proportion of } \\
\text { total consumption }\end{array}$ & $\begin{array}{c}\text { Proportion of krill biomass } \\
\text { Best estimate }\end{array}$ & Low estimate \\
\hline Herring & 73.18 & 0.707 & 0.00209 & 0.00279 \\
Cetaceans & 26.79 & 0.259 & 0.00076 & 0.00102 \\
Seabirds & 3.56 & 0.034 & 0.00010 & 0.00014 \\
Total & 103.53 & & 0.00296 & 0.00394 \\
\hline
\end{tabular}

Table 3. Estimates of fish and euphausiid prey consumption within the Platts Bank study area by the major groups of species reported. Basking sharks and molas do not take these prey and are not included

\begin{tabular}{|lcccc|}
\hline & $\begin{array}{c}\text { Mean individuals } \\
\text { sighted d }\end{array}$ & $\begin{array}{c}\text { Mass of an } \\
\text { individual (kg) }\end{array}$ & $\begin{array}{c}\text { Individual daily } \\
\text { consumption (kg) }\end{array}$ & $\begin{array}{c}\text { Total daily } \\
\text { consumption (kg) }\end{array}$ \\
\hline Humpback whale & 12.00 & 30000 & 1232.37 & 14788.5 \\
Fin whale & 1.30 & 25000 & 1412.95 & 1836.8 \\
Atlantic white-sided dolphin & 130.40 & 120 & 13.32 & 1737.5 \\
Gulls & 2153.78 & 1.375 & 0.62 & 1342.1 \\
Minke whale & 1.00 & 4500 & 340.56 & 340.6 \\
Shearwaters & 734.53 & 0.85 & 0.32 & 236.2 \\
Storm-petrels & 1029.76 & 0.035 & 0.03 & 32.7 \\
Northern gannet & 24.90 & 3.00 & 0.88 & 21.9 \\
Terns & 149.40 & 0.12 & 0.09 & 13.1 \\
Total & & & & $\mathbf{2 0 3 4 9}$ \\
\hline
\end{tabular}


speculate that it may have been due to the abundant Calanus finmarchicus indicated by our samples from the surface mixed layer.

Euphausiids were the primary prey during most foraging activity that we observed from the boat or from the air. All observed instances of surface feeding by fin whales and the majority of those by humpback whales were directed at euphausiid swarms. Similarly, both shearwaters and gulls were observed feeding heavily on euphausiids. This contrasts with published estimates of prey preference for these species in the Gulf of Maine, which indicate that they rely heavily on fish. Estimates of prey consumption for the Gulf of Maine and Georges Bank indicate that large gulls take (by weight) $15 \%$ euphausiids, fin whales $10 \%$ and humpback whales and shearwaters only $5 \%$ (Kenney et al. 1985, Powers \& Backus 1987). Our results show a high degree of opportunism that may shift these ratios under some conditions.

Internal waves, which are common throughout the southern Gulf of Maine (Haury et al. 1979, Jackson 2004), appear to be an important mechanism enhancing the transfer of energy from plankton to upper trophic levels on Platts Bank. We postulate that some physical aspect(s) of wave passage lead to the dense surface swarms. For example, shoaling of the pycnocline results in horizontal divergence of the overlying water and downwelling at zones of convergence between waves. Depending on the speeds, a rheotactic response to downwelling can result in accumulation near the surface front (Helfrich \& Pineda 2003). Schooling behavior might amplify these responses (O'Brien 1987). While we cannot resolve the mechanisms from these initial observations, there is ample evidence that they involve a coupling of physical processes and biological behavior: (1) Strong convergences at the surface show there was an abundance of small-scale flows where euphausiid swarms occurred. (2) The swarms commonly occurred without being forced by predators. (3) Euphausiids were actively swimming as they approached the surface, though their rapid subsequent decent indicates they preferred not to be there.

It is interesting that surface swarms and most of the whale surface feeding were concentrated near the 2 crests, since internal waves occurred everywhere we recorded, and euphausiids were similarly abundant (though highly patchy) throughout the study area. It seems likely that topography influenced the mechanism(s) of surface swarm formation, possibly by modulating the internal waves. That the whales tended to congregate around the crests and responded rapidly to the surface swarms indicates their adaptation to the prevailing patterns, even though these are not constant.
Surface swarms of euphausiids appear to be much denser than nearly all of the acoustic abundance estimates (no. $\mathrm{m}^{-2}$ ) below the surface. There was undoubtedly some visual bias towards the dense patches, but they nonetheless were common. Some difference between the acoustic record and visual observations may be explained by the small scale of patches (10s of $\mathrm{m}$ ) compared to the spatial resolution of sampling. Yet, the 1 to 2 orders of magnitude separating the estimates of surface swarm densities from the acoustic estimate of subsurface values is large. Potential sources of underestimation of euphausiids from the acoustic record include lack of a euphausiidspecific calibration for our instrument and non-random orientation of the animals such that acoustic backscatter was reduced (Stanton et al. 1994). Contrarily, assigning all of the backscatter that was typical of plankton to euphausiids would tend to overestimate their abundance (Lavery et al. 2003, Warren et al. 2003). In addition, patches did not form with the passage of every internal wave, which can be readily monitored in calm conditions. It is likely that there is a range of phenomena occurring, with waves of various amplitudes and patterns, patchy distributions of euphausiids, tidal forcing and other phenomena all influencing whether a dense patch appears at the surface. Cotté \& Simard (2005) described the aggregation of euphausiids in subsurface layers by an interaction among semidiurnal tidal forcing, topography and the negative phototactism of the krill Thysannoessa raschi and Meganyctiphanes norvegica in a location known for active feeding by whales and pelagic fish. The aggregation resulted in an increase of roughly $100 \times$ in the concentration (no. $\mathrm{m}^{-3}$ ) of euphausiids over background levels and maximum concentrations $\left(\mathrm{m}^{-3}\right)$ similar to ours. Pilot whale association with fronts created by large internal waves has been demonstrated in the South China Sea (Moore \& Lien 2007). Coyle et al. (1992) and Hunt et al. $(1996,1998)$ refer to feeding by birds in areas of concentrated prey induced by the shoaling of pycnoclines and prey layers (such as the euphausiid $T$. raschii) and frontal convergences. Although the details of prey behaviour and physical mechanisms vary, the results of all these studies point to the importance of highly localized phenomena in the feeding of many apex predators.

While surface swarms of euphausiids were the most visible manifestation of prey concentrations in the present study, the physical mechanisms reported here may also concentrate other prey types. We conducted shallow tows in surface slicks that formed between internal waves and found extremely high concentrations of calanoid copepods. These slicks were often frequented by storm-petrels which feed on near-surface plankton. 
While physical and behavioral factors may cause prey to aggregate at different points throughout the water column, prey at the surface is more readily utilized by predators because diving constraints are not a factor, and the sea surface forms a barrier to prey escapement. Thus, the locations at which the internal wave dynamics brought euphausiids to the surface saw the most active and intensive foraging activity. Our observations did not provide any evidence that seabirds were relying heavily on whales to drive euphausiids to the surface or that bird activity concentrated prey for whales (Evans 1982).

The estimated level of consumption by predators on the bank accounts for only a small proportion of the available euphausiid biomass. Even making a series of very conservative assumptions that maximize the consumption estimates to account for the uncertainty, the daily consumption is estimated to be $<0.004$ of the euphausiid biomass. Euphausiids are advected onto the bank by tidal and residual circulation and are thus resupplied over time. Even without the arrival of new individuals, however, consumption remains a small proportion of biomass. We observed comparable levels of activity each day that we surveyed, and abundant vertebrate predators were noted by others the week before we began this study (D. Wiley pers. comm.). If we assume, therefore, that the estimated consumption levels were representative of the entire month of July, all predators that we recorded consumed $3200 \mathrm{t}$ of euphausiids, or 0.12 of the low estimate of instantaneous euphausiid biomass. Thus, contrary to our initial expectations, top-down control is unlikely to substantially influence the biomass of prey available in this instance.

Not all of the predators in the study area were associated with the bank. Some individual animals that were sighted in other areas may have been in transit, searching or resting. For example, while humpback whales rest at the surface for extended periods, and may well be found at preferred feeding sites even when they are not foraging, fin whales swim continuously and are more likely to be sighted at a greater distance from foraging sites. Such differences in distribution do not necessarily indicate different foraging preferences. Certain species, however, showed a clear affinity for off-bank waters. These were primarily species that do not prey on euphausiids or herring. Pilot whales were exclusively seen in deep waters, and squid predominates in their diet (Gannon et al. 1997). Molas prey on gelatinous zooplankton (Collette \& Klein-MacPhee 2002). Basking sharks were the most uniformly distributed and prey largely on copepods (Collette \& Klein-MacPhee 2002). The terns were also frequently sighted in deeper water, but observations suggest that these were most commonly associated with drifting weed patches, wood or debris which were distributed widely across the study area.

We have considered a prominent set of interactions on the bank, but there are others that should be mentioned. The euphausiids themselves are opportunistic omnivores that were likely taking advantage of the abundant Calanus spp., as well as other prey items (Lass et al. 2001). Modest populations of demersal fish, shrimp, bivalved mollusks and cephalopods have been sampled by past resource surveys. There was some commercial gillnetting taking place while we were conducting this research, and cod and haddock comprised much of the catch. Small cod and haddock that we caught had euphausiids among the prey in their stomachs. It is possible that historic depletion of fish stocks in the region have altered the trophic dynamics, leading to less overall predation pressure and more bottom-up control (Frank et al. 2007). The bank is also known as a foraging spot for Atlantic bluefin tuna Thunnus thynnus, probably attracted by herring. Tuna were not evident at the surface while we were surveying, and the herring concentrations were not particularly great. Nonetheless, there is more taking place on the bank than we have represented in our calculations.

It is probable that a variety of mechanisms produce prey concentrations over banks and that the specific combination of mechanisms will vary between banks and over time. A lack of predictability in prey availability is to be anticipated at any feature, and this may be a function of the specific mechanisms acting at the site. Thus, apex predators need to employ a foraging strategy that allows them to investigate and utilize a series of feeding sites. The strategy used by specific predators will be a function of their mobility, energetic demands, costs and speed of transport, foraging patterns and relative foraging success that they encounter.

The steady use of this small bank by marine mammals and birds over a period of nearly $3 \mathrm{wk}$ suggests that it can serve as a significant feeding spot for highly mobile predators, despite its small size. Our calculations indicate that the amount of planktonic food did not become limiting during this period. However, the near-surface distributions of the prey appear to have been a major factor in the high functionality of the bank while we were there, and the processes that enable surface feeding may be ephemeral and may vary among years. Thus, the functioning of the bank may depend on bottom-up processes that cannot be defined strictly by the abundance of prey, but also by the interaction between these organisms and local physical processes. It is these coupled processes that must be considered as a driver for temporal variability on such banks, along with the feeding strategies and movements of dependent species. 
Acknowledgements. This work was conducted as part of the Gulf of Maine Census of Marine Life program. Our thanks to M. Bessinger, Y. Guilbault, K. Lagueux, H. McRae and B. Pike for assistance in the field and laboratory; J. Ambroult and pilot P. Kibler for aerial surveys; and Captain M. Greene of the MV 'Galatea'. A. Lavery provided advice on the interpretation of acoustic data, G. Sherwood advised us on herring consumption models, and L. Mayer provided recent multibeam data. We acknowledge financial support from the Alfred P. Sloan Foundation.

\section{LITERATURE CITED}

Ballance LT, Pitman RL, Reilly SB (1997) Seabird community structure along a productivity gradient: importance of competition and energetic constraint. Ecology 78: 1502-1518

Baumgartner MF, Cole TVN, Clapham PJ, Mate BR (2003) North Atlantic right whale habitat in the lower Bay of Fundy and on the SW Scotian Shelf during 1999-2001. Mar Ecol Prog Ser 264:137-154

Blix AS, Folkow LP (1995) Daily energetic expenditure of free-living minke whales. Acta Physiol Scand 153:61-66

Bowman RE, Stillwell CE, Michaels WL, Grosslein MD (2000) Food of northwest Atlantic fishes and two common species of squid. NOAA Technical Memorandum NMFS-NE-155. NOAA, Northeast Fisheries Science Center, Woods Hole, MA

> Campana SE, Joyce WN (2004) Temperature and depth associations of porbeagle shark (Lamna nasus) in the northwest Atlantic. Fish Oceanogr 13:52-64

Clarke A, Quetin LB, Ross RM (1988) Laboratory and field estimates of the rate of faecal pellet production by Antarctic krill, Euphausia superba. Mar Biol 98:557-563

Collette BB, Klein-MacPhee G (eds) (2002) Bigelow and Schroeder's fishes of the Gulf of Maine. Smithsonian Books, Washington, DC

> Cotté C, Simard Y (2005) Formation of dense krill patches under tidal forcing at whale feeding hot spots in the St. Lawrence Estuary. Mar Ecol Prog Ser 288:199-210

Coyle KO, Hunt GL, Decker MB, Weingartner TJ (1992) Murre foraging, epibenthic sound scattering and tidal advection over a shoal near St. George Island, Bering Sea. Mar Ecol Prog Ser 83:1-14

> Croll DA, Marinovic B, Benson S, Chavez FP, Black N, Ternullo R, Tershy BR (2005) From wind to whales: trophic links in a coastal upwelling system. Mar Ecol Prog Ser 289:117-130

De Robertis A (2001) Validation of acoustic echo counting for studies of zooplankton behavior. ICES J Mar Sci 58: 543-561

Ellis HI, Gabrielsen GW (2002) Energetics of free-ranging seabirds. In: Schreiber EA, Burger J (eds) Biology of marine birds. CRC Press, Boca Raton, FL, p 357-405

Evans PGH (1982) Associations between seabirds and cetaceans: a review. Mammal Rev 12:187-206

Fauchald P, Erikstad KE, Skarsfjord H (2000) Scale-dependent predator-prey interactions: the hierarchical spatial distribution of seabirds and prey. Ecology 81:773-783

- Foote KG (1987) Fish target strengths for use in echo integrator surveys. J Acoust Soc Am 82:981-987

Frank KT, Petrie B, Shackell NL (2007) The ups and downs of trophic control in continental shelf ecosystems. Trends Ecol Evol 22:236-242

Gannon DP, Read AJ, Craddock JE, Mead JG (1997) Stomach contents of long-finned pilot whales (Globicephala melas) stranded on the U.S. mid-Atlantic coast. Mar Mamm Sci 13:405-418

Haury LR, Briscoe MB, Orr MH (1979) Tidally-generated internal wave packets in Massachusetts Bay. Nature 278:312-317

Helfrich KR, Pineda J (2003) Accumulation of particles in propagating fronts. Limnol Oceanogr 48:1509-1520

Hunt GL, Coyle KO, Hoffman S, Decker MB, Flint EN (1996) Foraging ecology of short-tailed shearwaters near the Pribilof Islands, Bering Sea. Mar Ecol Prog Ser 141:1-11

> Hunt GL, Russell RW, Coyle KO, Weingartner TJ (1998) Comparative foraging ecology of planktivorous auklets in relation to ocean physics and prey availability. Mar Ecol Prog Ser 167:241-259

Jackson CR (2004) An atlas of internal, solitary-like waves and their properties, 2nd edn. Global Ocean Associates, Alexandria, VA

Kenney RD, Hyman MAM, Winn HE (1985) Calculation of standing stocks and energetic requirements of the cetaceans of the northeast United States outer continental shelf. NOAA Technical Memorandum NMFS-F/NEC-41. NOAA, Northeast Fisheries Science Center, Woods Hole, MA

Kenney RD, Scott GP, Thompson TJ, Winn HE (1997) Estimates of prey consumption and trophic impacts of cetaceans in the USA northeast continental shelf ecosystem. J Northwest Atl Fish Sci 22:155-171

Kleiber M (1975) The fire of life, an introduction to animal energetics. R. E. Kreiger Publishing, Huntington, NJ

Kotliar NB, Wiens JA (1990) Multiple scales of patchiness and patch structure: a hierarchical framework for the study of heterogeneity. Oikos 59:253-260

Kulka DW, Corey S (1982) Length and weight relationships of euphausiids and caloric values of Meganyctiphanes norvegica (M.Sars) in the Bay of Fundy. J Crustac Biol 2:239-247

Lass S, Tarling GA, Virtue P, Matthews JBL, Mayzaud P, Bucholtz F (2001) On the food of northern krill Meganyctiphanes norvegica in relation to its vertical distribution. Mar Ecol Prog Ser 214:177-200

> Lavery AC, Schmitt RW, Stanton TK (2003) High-frequency acoustic scattering from turbulent oceanic microstructure: the importance of density fluctuations. J Acoust Soc Am 114:2685-2697

> Lawson GL, Wiebe PH, Ashjian CJ (2006) Improved parameterization of Antarctic krill target strength models. J Acoust Soc Am 119:232-242

> Link JS (2002) What does ecosystem-based fisheries management mean? Fisheries 27:18-21

Lockyer C (1976) Body weights of some large whales. ICES J Mar Sci 36:259-273

Lockyer C (1981) Growth and energy budgets of large baleen whales from the Southern Hemisphere. In: Mammals in the seas, Vol 3. FAO Fish Ser (5)3:379-487

Lockyer C (1987) Evaluation of the role of fat reserves in relation to the ecology of North Atlantic fin and sei whales. In: Huntley AC, Costa DP, Worthy GAJ, Castellini MA (eds) Approaches to marine mammal energetics. Society for Marine Mammalogy Special Publication No. 1, p 183-203

> Love RH (1971) Dorsal-aspect target strength of an individual fish. J Acoust Soc Am 49:816-823

Mayo CA, Marx MK (1990) Surface foraging behaviour of the North Atlantic right whale, Eubalaena glacialis, and associated zooplankton characteristics. Can J Zool 68: 2214-2220

Montevecchi WA, Myers RA (1995) Prey harvests of seabirds 
reflect pelagic fish and squid abundance on multiple spatial and temporal scales. Mar Ecol Prog Ser 117:1-9

Moore SE, Lien RC (2007) Pilot whales follow internal solitary waves in the South China Sea. Mar Mamm Sci 23:193-196

Moum JN, Farmer DM, Smyth WD, Armi L, Vagle S (2003) Structure and generation of turbulence at interfaces strained by internal solitary waves propagating shoreward over the continental shelf. J Phys Oceanogr 33: 2093-2112

$>$ Nicol S (1984) Population structure of daytime swarms of the euphausiid Meganyctiphanes norvegica in the Bay of Fundy. Mar Ecol Prog Ser 18:241-251

Nicol S (2003) Living krill, zooplankton and experimental investigations: a discourse on the role of krill and their experimental study in marine ecology. Mar Freshwat Behav Physiol 36:191-205

Nicol S, O'Dor RK (1985) Predatory behavior of squid (Illex illicebrosus) feeding on surface swarms of euphausiids. Can J Zool 63:15-17

O'Brien DP (1987) Description of escape responses of krill (Crustacea: Euphausiacea), with particular reference to swarming behavior and the size and proximity of the predator. J Crustac Biol 7:449-457

Pauly D (1989) Food consumption by tropical and temperate fish populations: some generalizations. J Fish Biol 35 (Supplement A):11-20

Pettigrew NR, Churchill JH, Janzen CD, Mangum LJ and others (2005) The kinematic and hydrographic structure of the Gulf of Maine Coastal Current. Deep-Sea Res II 52: 2369-2391

Powers KD, Backus RH (1987) Energy transfer to seabirds. In: Backus RH, Bourne DW (eds) Georges Bank. MIT Press, Cambridge, MA, p 372-374

Schick RS, Goldstein J, Lutcavage ME (2004) Bluefin tuna (Thunnus thynnus) distribution in relation to sea surface temperature fronts in the Gulf of Maine (1994-1996). Fish Oceanogr 13:225-238

Sibley DA (2000) The Sibley guide to birds. Alfred A. Knopf, New York, NY

Editorial responsibility: Otto Kinne,

Oldendorf/Luhe, Germany
Sigurjónsson J, Vikingsson GA (1998) Seasonal abundance of and estimated food consumption by cetaceans in Icelandic and adjacent waters. J Northwest Atl Fish Sci 22:271-287

Stanton TK, Chu D (2000) Review and recommendations for the modelling of acoustic scattering by fluid-like elongated zooplankton: euphausiids and copepods. ICES J Mar Sci 57:793-807

Stanton TK, Wiebe PH, Chu D, Goodman L (1994) Acoustic characterization and discrimination of marine zooplankton and turbulence. ICES J Mar Sci 51:469-479

Steimle FW, Terranova RJ (1985) Energy equivalents of marine organisms from the continental shelf of the temperate Northwest Atlantic. J Northwest Atl Fish Sci 6:117-124

> Stevick PT (1999) Age-length relationships in humpback whales: a comparison of strandings in the western North Atlantic with commercial catches. Mar Mamm Sci 15: 725-737

Stevick PT, McConnell BJ, Hammond PS (2002) Patterns of movement. In: Hoelzel AR (ed) Marine mammal biology: an evolutionary approach. Blackwell Science, Oxford, p 185-216

- Warren JD, Stanton TK, Benfield MC, Wiebe PH, Chu D, Sutor M (2001) In situ measurements of acoustic target strengths of gas-bearing siphonophores. ICES J Mar Sci 58:740-749

Warren JD, Stanton TK, Wiebe PH, Seim HE (2003) Inference of biological and physical parameters in an internal wave using multiple-frequency, acoustic-scattering data. ICES J Mar Sci 60:1033-1046

Wood SN (2006) Generalised additive models - an introduction with R. Chapman Hall/CRS, Boca Raton, FL

- Worm B, Myers RA (2003) Meta-analysis of cod-shrimp interactions reveals top-down control in oceanic food webs. Ecology 84:162-173

Yen PPW, Sydeman WJ, Hyrenbach KD (2004) Marine bird and cetacean associations with bathymetric habitats and shallow-water topographies: implications for trophic transfer and conservation. J Mar Syst 50:79-99

Submitted: July 16, 2007; Accepted: March 6, 2008

Proofs received from author(s): June 26, 2008 